\section{União interétnica de nipo-brasileiros associada a hábitos alimentares menos saudáveis e ao pior perfil de risco cardiometabólico}

\author{
Interethnic marriage of Japanese-Brazilians associated with \\ less healthy food habits and worse cardiometabolic profile
}

Carla Yamashita', Renata Damião², Rita Chaim³ ${ }^{3}$, Helena Aiko Harima ${ }^{4}$, Mário Kikuchi $^{4}$, Laércio J. Franco ${ }^{5}$, Sandra Roberta G. Ferreira ${ }^{6}$ em nome do JBDS Group (Apêndice)*

\section{RESUMO}

Objetivo: Casamento interétnico entre brasileiros nikkeis e não nikkeis pode favorecer a ocidentalização da dieta. Compararam-se consumo alimentar, dados clínico-laboratoriais e frequências de doenças metabólicas em população nipo-brasileira, com casamento intraétnico ou interétnico. Métodos: Empregaram-se teste t, Mann-Whitney, qui-quadrado e coeficiente de Pearson. Resultados: Em 1009 nipo-brasileiros havia 18,9\% de casamentos interétnicos, mais frequentes entre homens nikkeis. Estes apresentaram maiores médias de IMC, cintura, pressão arterial, glicemia e triglicérides que mulheres. As frequências de obesidade, hipertrigliceridemia e síndrome metabólica foram $47,7 \%, 68,1 \%$ e 45,2\%, sendo maiores nos casamentos interétnicos comparados aos intraétnicos. Comparando-se indivíduos com casamento interétnico, hipertrigliceridemia foi mais frequente nos homens e HDL-c baixo nas mulheres. $\mathrm{O}$ consumo de calorias, gorduras e dos grupos de álcool, doces e óleos foram maiores nos casamentos interétnicos. Indivíduos casados intraetnicamente consumiam mais carboidratos, proteínas, fibras, vitaminas, minerais, hortaliças, frutas/sucos, cereais e missoshiru. Comparando-se indivíduos com casamento interétnico, homens nikkeis apresentavam padrão mais ocidental que mulheres nikkeis. Conclusão: Casamento interétnico associa-se a hábitos alimentares menos saudáveis e pior perfil de risco cardiometabólico. Arq Bras Endocrinol Metab. 2009;53(5):485-96.

Descritores

Dieta; ocidentalização; migrantes japoneses; morbidade; casamento; miscigenação; risco cardiometabólico
' Programa de Pós-Graduação em Nutrição em Saúde Pública, Faculdade de Saúde Pública, Universidade de São Paulo (USP), São Paulo, SP, Brasil ${ }^{2}$ Universidade Federal do Triângulo Mineiro (UFTM), Uberaba, MG, Brasil

${ }^{3}$ Faculdade de Nutrição, Universidade do Sagrado Coração (USC), Bauru, SP, Brasil ${ }^{4}$ Departamento de Medicina Preventiva, Universidade Federal de São Paulo (Unifesp), São Paulo, SP, Brasil ${ }^{5}$ Departamento de Medicina Social, Faculdade de Medicina de Ribeirão Preto (FMRP), USP, São Paulo, SP, Brasil

${ }^{6}$ Departamento de Nutrição, Faculdade de Saúde Pública USP, São Paulo, SP, Brasil

\begin{abstract}
Objective: Interethnic marriage between nikkey Brazilians and non-nikkey Brazilians may favor the westernization of diet. Dietary consumption, clinical data and frequencies of metabolic diseases were compared in a Japanese-Brazilian population, with intraethnic or interethnic marriage. Methods: T test, Mann-Whitney, chi-square and Person coefficient were used. Results: Among 1009 Japanese-Brazilians there were $18.9 \%$ of interethnic marriage, being more frequent among nikkey men. These showed higher means of BMI, waist, blood pressure, glycemia and triglyceridemia than women. Overall frequencies of obesity, hypertrigliceridemia and metabolic syndrome were $47.7 \%, 68.1 \%$ and $45.2 \%$, being higher in interethnic than intraethnic marriage. Comparing individuals with interethnic marriages, hypertriglyceridemia was more common among men while low-HDL among women. Energy, fat, groups of alcohol, sweets and oils were higher in interethnic marriage. Individuals with intraethnic marriage consumed more carbohydrate, proteins, fibers, vitamins, minerals, vegetables, fruits/juice, cereals and missoshiru. Comparing individuals with interethnic marriages, nikkey men showed a more westernized dietary pattern than nikkey women. Conclusion: Interethnic marriage was associated with less healthy food habits and worse cardiometabolic profile. Arq Bras Endocrinol Metab. 2009;53(5):485-96.
\end{abstract}

Keywords

Diet; westernization; Japanese migrants; morbidity; marriage; miscegenation; cardiometabolic risk
Correspondência para: Sandra Roberta G. Ferreira Departamento de Nutrição, Faculdade de Saúde Pública da Universidade de São Paulo Av. Doutor Arnaldo, 715, 2andar 01246-904 - São Paulo, SP, Brasil sandrafv@usp.br

Recebido em 27/Mar/2009 Aceito em 16/Jun/2009 


\section{INTRODUÇÃO}

$\mathrm{E}$ studos de populações migrantes permitem comparar grupos que se deslocaram para regiões com diferentes hábitos de vida, sendo úteis para avaliar a participação de fatores ambientais na gênese de doenças crônicas $(1,2)$. Originariamente, a população do Japão caracterizava-se por baixa morbimortalidade por diabetes melito (DM) e doença cardiovascular, mas mudanças socioculturais no Ocidente elevaram o risco nos imigrantes japoneses nas Américas (1,3-8).

$\mathrm{O}$ quadro da morbimortalidade de nipo-americanos motivou pesquisadores do Japanese-Brazilian Diabetes Study (JBDS) a realizar estudos sobre o impacto do ambiente ocidental na saúde da população nipo-brasileira (9), já que o Brasil conta com a maior comunidade nikkei residente fora do Japão (10). Encontrou-se, em nipo-brasileiros residentes em Bauru, São Paulo, prevalência de obesidade geral de $40 \%$ e de obesidade central de cerca de $50 \%$ (maior prevalência na segunda geração comparada à primeira). A obesidade central associouse aos clássicos fatores de risco cardiovascular (dislipidemia, hipertensão arterial e DM) (8), sendo que $45 \%$ dos nipo-brasileiros foram considerados portadores de síndrome metabólica (SM) (11).

Sabe-se que fatores relacionados ao estilo de vida ocidental, como certos padrões alimentares, sedentarismo e estresse psicossocial, associados à predisposição genética, contribuem para deposição de gordura visceral, geradora de resistência à insulina e SM. O papel da dieta na gênese dessas doenças é tema de interesse global. Comparando o padrão dietético de descendentes de japoneses residentes em São Paulo ao de japoneses do Japão, observou-se consumo mais elevado de óleos e gorduras, carne vermelha, frango e laticínios pelos primeiros (12). Conhecendo-se o impacto deletério das gorduras saturadas no perfil lipídico, é possível que a maior mortalidade cardiovascular encontrada em nipobrasileiros (13) possa ser parcialmente decorrente do padrão dietético assumido no Brasil.

De fato, comprovou-se que o atual cardápio dos nipo-brasileiros é muito semelhante à dieta brasileira, a qual é rica em gorduras e proteínas. Inquérito alimentar realizado nos nipo-brasileiros de Bauru revelou elevado consumo de gorduras totais (14). Em inquérito posterior, observou-se que a ingestão desse macronutriente havia aumentado em 16\% (15). Entre os homens da mesma população, o consumo de carnes vermelhas (provavelmente em decorrência de seu conteúdo de gordura saturada) se associou à ocorrência de SM (16).
O consumo de certos carboidratos também foi associado a risco de distúrbios da homeostase glicêmica em nipo-brasileiros com alto consumo de frutas e sucos de frutas, pão branco e arroz polido - alimentos típicos da dieta brasileira (17).

Comportamento menos saudável do sexo masculino em relação aos hábitos alimentares pode contribuir para a maior prevalência de doenças crônicas e menor expectativa de vida quando comparado às mulheres $(18,19)$. As diferenças no comportamento de risco segundo sexo são consistentes, independente da raça ou etnia (19).

A hipótese do presente estudo foi a de que, no que diz respeito a hábitos alimentares, o casamento interétnico favorece a ocidentalização dos costumes dos imigrantes japoneses no Brasil. Essa situação poderia predispor à deposição de gordura corporal e a fatores de risco cardiometabólico. Partiu-se do pressuposto de que, no lar, a mulher tem maior influência do que o homem sobre a dieta oferecida.

Este estudo comparou o consumo alimentar, as medidas antropométricas, as variáveis bioquímicas e a prevalências de distúrbios do metabolismo glicolipídico e hipertensão arterial na população nipo-brasileira, participante da segunda fase do JBDS, entre indivíduos com casamento intraétnico (nikkei com nikkei) ou interétnico (nikkei com não nikkei). Analisou-se, ainda, a hipótese de, em um casal interétnico, o sexo do cônjuge não nikkei estar associado a diferentes impactos nesses parâmetros.

\section{MÉTODOS}

\section{População de estudo}

A população de estudo foi a de nipo-brasileiros não miscigenados (puramente nikkei) que participaram da segunda fase do Estudo de Diabetes e Doenças Associadas na População Nipo-Brasileira de Bauru, realizada em 2000, em São Paulo. Todos os participantes dessa pesquisa assinaram o termo de consentimento, e o estudo foi aprovado pelo Comitê de Ética da Universidade Federal de São Paulo (Unifesp). Detalhamento metodológico do estudo conduzido em 2000 foi previamente publicado (7). Resumidamente, a população nipo-brasileira convidada para a segunda fase do estudo foi de primeira (nascidos no Japão) e segunda (nascidos no Brasil) gerações, de ambos os sexos, com 30 anos de idade ou mais. Da totalidade de 1.651 identificados, participaram 1.330 indivíduos. Estes foram entrevistados no domicílio, quando eram agendados para exames clínico-laboratoriais em jejum no Hospital de Lesões 
Lábio-Palatais de Bauru. Dados sociodemográficos, dietéticos, clínicos e laboratoriais foram armazenados em banco de dados.

Dos 1.330 participantes, todos os indivíduos casados foram selecionados para constituir a atual casuística. Após a exclusão dos não casados, restaram 1.009 indivíduos elegíveis (818 no grupo de casamento intraétnico e 191 no interétnico), os quais dispunham dos dados coletados. Destes 1.009 incluídos, para fins de análises dietéticas, foram excluídos 35 indivíduos que não apresentavam dados de consumo alimentar completos e 18 que tinham valores de energia abaixo do percentil $\mathrm{l} \mathrm{e}$ acima do percentil 99, caracterizando, respectivamente, sub e superestimação da ingestão (20). Para responder ao objetivo, a população incluída foi estratificada segundo o tipo de casamento.

\section{Método}

O delineamento do presente estudo é transversal, de base populacional, desenvolvido no banco de dados previamente elaborado. Em visitas domiciliares, entrevistadores treinados coletaram dados sociodemográficos e alimentares, por meio de questionários padronizados. Os dados dietéticos foram obtidos utilizando questionário quantitativo de frequência alimentar composto por 122 itens, desenvolvido e validado para a população nipo-brasileira $(21,22)$.

A entrevista alimentar considerou o consumo habitual de alimentos e bebidas relativo ao período de um ano anterior ao momento da aplicação do questionário alimentar. Os participantes informaram a frequência habitual de consumo, a unidade de tempo (diária, semanal, mensal ou anual) e o tamanho da porção (pequena, média, grande ou ultragrande). Questões relativas ao uso de molhos, à frequência de gorduras visíveis e ao tipo destas usado para cocção foram anotadas. A codificação dos inquéritos alimentares foi duplamente conferida e a consistência interna, verificada. O processamento e a análise dos dados dietéticos foram realizados pelo Dietsys 4.01 (National Cancer Institute, Bethesda, Maryland, Estados Unidos). A base de dados alimentares primária é a do US Department of Agriculture, que foi suplementada pela Tabela de Composição de Alimentos do Brasil (23) e Japão (24). As variáveis selecionadas para este estudo foram: calorias totais, carboidratos, proteína, gordura total, saturada, ácido oleico, ácido linoleico, colesterol, fibras, alguns micronutrientes que mostram relação com doenças cardiometabólicas e nove grupos de alimentos (1. álcool; 2 . doces; 3 . hortaliças; 4 . frutas e suco de frutas; 5 . cereais, pães, arroz e macarrão (grupo de cereais); 6. leites e derivados; 7. carnes, aves, peixes, ovos e feijões (grupo de carnes); 8. óleo, gordura e snacks (grupo de óleos); 9. missoshiru. Os macronutrientes foram considerados em valores absolutos e relativos às calorias totais.

A atividade física foi avaliada por questionário incluindo itens relativos a tipo e duração de atividades realizadas no trabalho e lazer (25). A classificação das atividades físicas seguiu a utilizada em estudo populacional de nipo-americanos de Seattle, Estados Unidos (Fujimoto W, comunicação pessoal). Um escore foi atribuído a cada indivíduo, classificados em três categorias: sedentário-leve, moderada e pesada.

No exame físico, de interesse para esse estudo, foram obtidos dados antropométricos e de pressão arterial. $\mathrm{O}$ peso (balança digital com capacidade para $150 \mathrm{~kg}$ e precisão de $100 \mathrm{~g}$ ) e a altura (estadiômetro fixo) foram medidos com os indivíduos usando roupas mínimas e sem calçados. A circunferência abdominal (fita métrica inextensível) foi medida na altura do umbigo, com indivíduo em pé, abdome relaxado, braços ao longo do corpo e pés unidos. O índice de massa corporal (IMC) foi calculado dividindo-se o peso $(\mathrm{kg})$ pelo quadrado da altura $(\mathrm{m})$. A obesidade generalizada segundo critérios para asiáticos foi definida como IMC $\geq 25 \mathrm{~kg} / \mathrm{m}^{2}$ e a obesidade central, como circunferência abdominal $\geq 90 \mathrm{~cm}$ para homens e $\geq 80 \mathrm{~cm}$ para mulheres (26). A composição corporal foi avaliada pela bioimpedância (modelo BIA 101Q, RJL System, Clinton Township, Michigan, USA) e a massa gorda foi expressa em porcentagem. A pressão arterial foi medida três vezes com aparelho automático (Omron model HEM-712C, Omron Health Care, USA) e o valor médio das duas últimas medidas foi usado para expressar as pressões sistólica e diastólica. Definiu-se hipertensão arterial para valores $\geq 140 \times 90 \mathrm{mmHg}$ (27).

Foram obtidas amostras de sangue após jejum de dez horas, sendo os indivíduos não diabéticos submetidos a teste oral de tolerância à glicose com $75 \mathrm{~g}$. A glicose plasmática foi dosada pelo método da glicooxidase e o perfil lipídico, determinado enzimaticamente em analisador automático (Cobas-Miraplus ${ }^{\circledR}$, Roche). O diagnóstico de DM foi baseado nos critérios da Associação Americana de Diabetes (28), que considera o valor de glicemia de jejum de $>125 \mathrm{mg} / \mathrm{dL}$.

Para dislipidemia, utilizaram-se os critérios do $\mathrm{Na}$ tional Cholesterol Education Program (29). Esse diagnóstico foi estabelecido para concentrações de coles- 
terol total $\geq 200 \mathrm{mg} / \mathrm{dL}$, LDL-colesterol $\geq 130 \mathrm{mg} /$ $\mathrm{dL}$, triglicérides $\geq 150 \mathrm{mg} / \mathrm{dL}$ ou HDL-colesterol $(\mathrm{HDL}-\mathrm{c}) \leq 40 \mathrm{mg} / \mathrm{dL}$ para o sexo masculino, ou $\leq 50$ $\mathrm{mg} / \mathrm{dL}$ para o sexo feminino.

A SM foi caracterizada segundo critérios da International Diabetes Federation (30), devendo o indivíduo apresentar obesidade central (circunferência abdominal $\geq 90 \mathrm{~cm}$ para homens e $\geq 80 \mathrm{~cm}$ para mulheres) e mais dois dos seguintes fatores: triglicérides $\geq 150 \mathrm{mg} / \mathrm{dL}$, HDL-c $\leq 40 \mathrm{mg} / \mathrm{dL}$ para homens ou $\leq 50 \mathrm{mg} / \mathrm{dL}$ para mulheres, pressão arterial $\geq 130$ × $85 \mathrm{mmHg}$, glicose de jejum $\geq 100 \mathrm{mg} / \mathrm{dL}$. Considerou-se, também, o autorrelato dessas anormalidades e/ou uso de medicações específicas.

\section{Análise estatística}

A população foi comparada segundo o tipo de casamento e o sexo. Também a amostra de casamento interétnico foi estratificada pelo sexo do cônjuge (homens nipobrasileiros casados com não nikkeis e mulheres nipobrasileiras casadas com não nikkeis). Estatística descritiva da população foi apresentada, sendo as variáveis numéricas com distribuição normal (avaliada pelo teste Kolmogorov-Smirnov) expressas em médias e desviospadrão. Aquelas sem distribuição normal foram transformadas em logaritmo. O teste $t$ de Student foi usado para comparar as médias das variáveis de interesse. Os dados dietéticos foram expressos em gramas ou como porcentagens do valor calórico total (VCT), sendo ajustados para energia total, usando o método do resíduo (31). As variáveis de grupos de alimentos foram apresentadas em mediana e intervalo interquartil e o teste Mann-Whitney foi usado nas comparações entre os estratos. Foram calculadas as frequências de morbidades nos diferentes estratos, comparadas pelo $\chi^{2}$. Foram testadas correlações entre o VCT, o consumo alimentar e nutrientes e os valores bioquímicos, antropométricos e as anormalidades metabólicas por meio do coeficiente de correlação de Pearson. O nível de significância foi fixado em 0,05. A análise estatística foi realizada com o auxílio do programa Statistical Package for Social Sciences, versão 12.0 (SPSS Inc. Woking, Surrey, UK).

\section{RESULTADOS}

Entre os 1.009 indivíduos que integraram a população nipo-brasileira casada, apenas $18 \%$ pertenciam à primeira geração (Tabela 1). Observou-se leve predomínio de homens $(52,6 \%)$ em relação às mulheres $(47,4 \%)$, sendo a média de idade semelhante entre os sexos. O nível de escolaridade foi maior entre os homens. Verificou-se que $18,9 \%$ de casamentos eram interétnicos, sendo estes mais frequentes entre os homens. Dados estratificados por geração não estão mostrados em tabelas. Conforme esperado, para ambos os sexos, o casamento interétnico predominou na segunda geração (22 versus $5,5 \% ; \mathrm{p}<0,001)$. A maioria dos indivíduos relatou atividade física leve, sendo as mulheres mais inativas do que os homens $(\mathrm{p}=0,014)$. Não foram observadas diferenças quanto à atividade física entre as gerações, quando estratificados por sexo.

Os valores médios de IMC e circunferência abdominal (Tabela 1) foram maiores entre os homens do que entre as mulheres, sendo apenas os primeiros classificados, em média, como obesos (IMC $\geq 25 \mathrm{~kg} / \mathrm{m}^{2}$ ). Porém, a porcentagem de gordura corporal foi maior nas mulheres que, em média, foram classificadas como tendo obesidade abdominal (circunferência abdominal $>80 \mathrm{~cm}$ ). Quando a circunferência abdominal foi estratificada por geração, observou-se diferença significante apenas entre o sexo masculino, sendo superior na segunda geração $(89,1$ versus $85,9 \mathrm{~cm} ; \mathrm{p}=0,001)$.

Os homens, comparados às mulheres, apresentaram valores médios superiores de pressão arterial sistólica e diastólica, glicose de jejum, triglicérides, ácido úrico e creatinina (Tabela 1). Apenas as concentrações de HDL-c foram significantemente maiores no sexo feminino, não havendo diferença estatisticamente significante entre os sexos em relação ao colesterol total e ao LDL-colesterol. Nota-se que as médias de glicemia e trigliceridemia da população, independente do sexo, estiveram acima da normalidade.

Dos 956 indivíduos considerados nas análises dietéticas, 502 eram homens $(52,5 \%)$ e $454(47,5 \%)$ mulheres. A tabela 2 mostra os valores médios brutos de VCT e nutrientes selecionados, embora, para fins estatísticos, a comparação por sexo e por tipo de casamento tenha ocorrido com valores ajustados pelo método do resíduo. Na tabela 2, observa-se que a média do VCT dos homens foi maior do que a das mulheres. Os homens consumiram mais proteínas e gorduras totais (em termos absolutos), gordura saturada, ácidos graxos oleico, ácido graxo linoleico e fibras.

\section{Estratificação por tipo de casamento e sexo}

Considerando a totalidade dos casamentos, independente do tipo e sexo, as prevalências de obesidade generalizada, obesidade central e SM foram, respectivamente, de $47,7,46,3$ e $45,2 \%$, sendo a hipertrigliceridemia $(68,1 \%)$ a anormalidade metabólica mais frequente. 


\begin{tabular}{|c|c|c|c|c|}
\hline Variáveis & $\begin{array}{c}\text { Total } \\
\mathrm{n}=1.009\end{array}$ & $\begin{array}{l}\text { Homens } \\
n=531\end{array}$ & $\begin{array}{c}\text { Mulheres } \\
\mathrm{n}=\mathbf{4 7 8}\end{array}$ & Valor de $p$ \\
\hline $1^{\mathrm{a}}$ geração (\%) & 18,0 & 21,3 & 14,4 & 0,005 \\
\hline Idade (anos) & $56,6(11,6)$ & $57,3(12,2)$ & $55,7(11,0)$ & 0,057 \\
\hline Anos de estudo no Brasil (\%) & & & & 0,000 \\
\hline Analfabeto & 1,8 & 0,4 & 3,4 & \\
\hline Sabe ler e escrever & 8,7 & 11,3 & 5,7 & \\
\hline 1 a 4 anos & 36,3 & 28,7 & 44,7 & \\
\hline 5 a 8 anos & 10,3 & 9,8 & 10,9 & \\
\hline 9 a 11 anos & 18,5 & 19,3 & 17,6 & \\
\hline Mais de 12 anos & 24,4 & 30,4 & 17,6 & \\
\hline Tipo de casamento & & & & 0,000 \\
\hline Intraétnico & 81,1 & 73,8 & 89,1 & \\
\hline Interétnico & 18,9 & 26,2 & 10,9 & \\
\hline Atividade física no lazer (\%) & & & & 0,014 \\
\hline Sedentário/leve & 83,8 & 80,8 & 87,2 & \\
\hline Moderada & 14,7 & 17,1 & 11,9 & \\
\hline Pesada & 1,5 & 2,1 & 0,8 & \\
\hline Índice de massa corporal (kg/m²) & $25,1(3,8)$ & $25,3(3,7)$ & $24,8(3,9)$ & 0,027 \\
\hline Circunferência abdominal (cm) & $84,6(10,1)$ & $88,4(9,3)$ & $80,4(9,2)$ & 0,000 \\
\hline Gordura corporal (\%) & $25,4(7,8)$ & $21,6(6,8)$ & $29,6(6,6)$ & 0,000 \\
\hline \multicolumn{5}{|l|}{ Pressão arterial (mmHg) } \\
\hline Sistólica & $133(23)$ & $135(22)$ & $130(24)$ & 0,000 \\
\hline Diastólica & $79(13)$ & $82(13)$ & $77(13,4)$ & 0,000 \\
\hline Glicemia de jejum (mg/dL) & $126(35)$ & $128(34)$ & $123(36)$ & 0,001 \\
\hline Colesterol total (mg/dL) & $214(43)$ & $212(41)$ & $217(44)$ & 0,072 \\
\hline HDL-colesterol (mg/dL) & $50(11)$ & $49(12)$ & $52(10)$ & 0,001 \\
\hline LDL-colesterol (mg/dL) & $130(38)$ & $128(37)$ & $132(39)$ & 0,073 \\
\hline Triglicérides ${ }^{\sharp}(\mathrm{mg} / \mathrm{dL})$ & $242(196)$ & $268(211)$ & $212(172)$ & 0,000 \\
\hline Ácido úrico (mg/dL) & $6,3(1,8)$ & $7,1(1,9)$ & $5,3(1,3)$ & 0,000 \\
\hline Creatinina (mg/dL) & $0,8(0,3)$ & $0,9(0,3)$ & $0,7(0,2)$ & 0,000 \\
\hline
\end{tabular}

\# Transformação logarítmica para análise estatística.

\begin{tabular}{|c|c|c|c|c|}
\hline Variáveis & $\begin{array}{c}\text { Total } \\
n=956\end{array}$ & $\begin{array}{l}\text { Homens } \\
\mathrm{n}=502\end{array}$ & $\begin{array}{c}\text { Mulheres } \\
\mathrm{n}=\mathbf{4 5 4}\end{array}$ & Valor de $\mathrm{p}$ \\
\hline $\mathrm{VCT}^{*}(\mathrm{kcal})$ & $2.026(569)$ & $2.162(567)$ & $1.876(533)$ & 0,000 \\
\hline \multicolumn{5}{|l|}{ Carboidrato } \\
\hline$g^{*}$ & $270,1(82,0)$ & $286,4(81,5)$ & $252,1(78,7)$ & 0,495 \\
\hline$\% \mathrm{VCT}$ & $53,5(7,4)$ & $53,2(7,7)$ & $53,7(7,0)$ & 0,648 \\
\hline \multicolumn{5}{|l|}{ Proteína } \\
\hline$g^{*}$ & $69,3(22,9)$ & $73,0(22,9)$ & $65,3(22,2)$ & 0,024 \\
\hline$\% \mathrm{VCT}$ & $13,7(2,5)$ & $13,5(2,5)$ & $13,9(2,5)$ & 0,030 \\
\hline \multicolumn{5}{|l|}{ Gordura total } \\
\hline$g^{*}$ & $73,4(25,1)$ & $76,9(26,1)$ & $69,5(23,3)$ & 0,000 \\
\hline$\% \mathrm{VCT}$ & $32,5(6,2)$ & $31,8(6,1)$ & $33,3(6,2)$ & 0,000 \\
\hline Colesterol dietético $(\mathrm{mg})^{\sharp}$ & $196,0(105,6)$ & $214,4(117,6)$ & $175,6(86,0)$ & 0,479 \\
\hline Gordura saturada $(\mathrm{g})^{\#}$ & $17,6(7,1)$ & $18,4(7,3)$ & $16,6(6,9)$ & 0,001 \\
\hline Ácido graxo oleico $(\mathrm{g})^{\#}$ & $27,6(9,8)$ & $28,8(10,3)$ & $26,3(9,1)$ & 0,000 \\
\hline Ácido graxo linoleico $(\mathrm{g})^{*}$ & $11,6(4,3)$ & $12,0(4,5)$ & $11,3(4,0)$ & 0,000 \\
\hline Fibra dietética $(\mathrm{g})^{*}$ & $17,9(7,5)$ & $18,7(7,8)$ & $17,1(7,1)$ & 0,035 \\
\hline
\end{tabular}


No subgrupo de casamentos interétnicos, observaram-se maiores prevalências de obesidade generalizada, obesidade central, hipertrigliceridemia e SM, quando comparadas às dos casamentos intraétnicos (Tabela 3 ). Estratificadas por sexo, nota-se que essas diferenças nas prevalências ocorreram por conta dos homens nikkeis com casamento interétnico. As mulheres nikkeis com casamento interétnico, comparadas às com intraétnico, apresentaram prevalências maiores de obesidade central e de $\mathrm{DM}$, e a diferença quanto à prevalência de $S M$ foi marginalmente significante $(\mathrm{p}=0,053)$.

Comparando-se entre si homens nikkeis e mulheres nikkeis com casamento interétnico, a prevalência de hipertrigliceridemia foi maior nos homens, enquanto a de HDL-c baixo foi maior nas mulheres.

Não foram observadas diferenças estatísticas na prevalência de hipertensão arterial e hipercolesterolemia (tanto níveis de colesterol total quanto de LDLcolesterol alterados) - quer em comparação por tipo de casamento, quer por sexo.

Dados de consumo alimentar, segundo o tipo de casamento e sexo, estão na tabela 4 e na figura $1 . \mathrm{Na}$ totalidade de nipo-brasileiros casados, independente do sexo, os valores médios do VCT, carboidrato e proteína em termos absolutos, gordura total, colesterol dietético, gordura saturada, ácido graxo oleico e linoleico foram significantemente maiores no grupo com casamento interétnico. Esses mesmos indivíduos também apresentaram medianas de consumo dos grupos de alimentos álcool, doces e óleos maiores, quando comparados àqueles com casamento intraétnico. Por outro lado, indivíduos com casamento intraétnico consumiam, em média, mais carboidratos e proteínas em relação ao
VCT. Também as medianas foram maiores para os grupos de alimentos hortaliças, frutas e sucos de frutas, cereais e missoshiru nos casados intraetnicamente.

Estratificando-se o consumo por sexo, o comportamento de homens e mulheres foi semelhante. Nos homens nikkeis com casamento interétnico, observaram-se médias maiores de VCT, ingestão de gordura total, gordura saturada, ácidos graxos oleico e linoleico, proteína e carboidrato, em termos absolutos, e medianas maiores dos grupos de alimentos doces e óleos, quando comparados ao grupo casado com não nikkeis. Homens com casamento intraétnico apresentaram maior consumo de carboidrato em relação ao VCT e dos grupos de hortaliças, frutas e sucos de frutas e missoshiru. Quanto às mulheres, aquelas com casamento interétnico apresentaram maiores médias de consumo de gordura total, gordura saturada e ácido graxo oleico e maiores medianas dos grupos de álcool e de óleo. Nas mulheres com casamento intraétnico, verificou-se maior ingestão de carboidrato, proteína e dos grupos de cereais e de missoshiru.

As médias de consumo de fibra, certas vitaminas (exceto vitamina E) e minerais estudados foram significantemente maiores no casamento intraétnico, tanto na totalidade, como estratificado por sexo.

Detendo-se apenas aos casamentos interétnicos, compararam-se os consumos de homens nikkeis e de mulheres nikkeis que se casaram com brasileiros não nikkeis. Os homens nikkeis apresentaram consumos significantemente maiores de calorias totais, gordura em termos absolutos (em g), ácidos graxos oleico e linoleico, vitamina $\mathrm{E}$ e dos grupos de álcool, cereais e carnes do que as mulheres nikkeis (Tabela 4 ). Somente a ingestão relativa de gordura foi maior no sexo feminino.

\begin{tabular}{|c|c|c|c|c|c|c|c|c|c|}
\hline \multirow[b]{2}{*}{ Variáveis } & \multicolumn{3}{|c|}{ Total de casados } & \multicolumn{3}{|c|}{ Homens } & \multicolumn{3}{|c|}{ Mulheres } \\
\hline & $\begin{array}{c}\text { Intraétnico } \\
\mathrm{n}=\mathbf{8 1 8}\end{array}$ & $\begin{array}{c}\text { Interétnico } \\
\mathrm{n}=191\end{array}$ & $\begin{array}{l}\text { Valor } \\
\text { de } p\end{array}$ & $\begin{array}{c}\text { Intraétnico } \\
\mathrm{n}=392\end{array}$ & $\begin{array}{c}\text { Interétnico } \\
n=139\end{array}$ & $\begin{array}{l}\text { Valor } \\
\text { de } p\end{array}$ & $\begin{array}{c}\text { Intraétnico } \\
n=426\end{array}$ & $\begin{array}{c}\text { Interétnico } \\
n=52\end{array}$ & $\begin{array}{l}\text { Valo } \\
\text { de } p\end{array}$ \\
\hline Obesidade generalizada & 44,7 & 60,7 & 0,000 & 47,7 & 64,0 & 0,001 & 41,9 & 51,9 & 0,167 \\
\hline Obesidade central & 44,3 & 55,0 & 0,007 & 39,8 & 51,1 & 0,021 & 48,4 & 65,4 & 0,020 \\
\hline Diabetes melito & 35,7 & 40,3 & 0,239 & 41,2 & 37,4 & 0,437 & 30,7 & 48,1 & 0,012 \\
\hline Hipertensão arterial & 44,2 & 45,0 & 0,833 & 47,1 & 46,8 & 0,952 & 41,5 & 40,4 & 0,872 \\
\hline Colesterol $\geq 200 \mathrm{mg} / \mathrm{dL}$ & 62,1 & 64,4 & 0,555 & 59,4 & 64,7 & 0,271 & 64,6 & 63,5 & 0,877 \\
\hline LDL-c $\geq 130 \mathrm{mg} / \mathrm{dL}$ & 49,0 & 47,6 & 0,743 & 44,8 & 46,0 & 0,435 & 52,8 & 51,9 & 0,903 \\
\hline Hipertrigliceridemia & 66,5 & 75,1 & 0,023 & 71,9 & 83,7 & 0,006 & 61,5 & $52,0^{*}$ & 0,193 \\
\hline HDL-c baixo & 30,7 & 25,1 & 0,130 & 16,6 & 17,3 & 0,853 & 43,7 & $46,2^{*}$ & 0,733 \\
\hline Síndrome metabólica & 42,9 & 55,4 & 0,003 & 39,8 & 53,4 & 0,007 & 45,8 & 60,9 & 0,053 \\
\hline
\end{tabular}

${ }^{*} p<0,001$ versus homens com casamento interétnico. 
Tabela 4. Valor calórico total e consumo diário de nutrientes ajustado para calorias totais e de grupos de alimentos da população nipo-brasileira casada segundo o tipo de casamento e sexo. Dados expressos em média (desvio-padrão) ou mediana (intervalo interquartil)

\begin{tabular}{|c|c|c|c|c|c|c|c|c|c|}
\hline \multirow[b]{2}{*}{ Variáveis } & \multicolumn{3}{|c|}{ Total } & \multicolumn{3}{|c|}{ Homens } & \multicolumn{3}{|c|}{ Mulheres } \\
\hline & $\begin{array}{c}\text { Intraétnico } \\
\mathrm{n}=778\end{array}$ & $\begin{array}{c}\text { Interétnico } \\
n=178\end{array}$ & $\begin{array}{l}\text { Valor } \\
\text { de } p\end{array}$ & $\begin{array}{c}\text { Intraétnico } \\
n=370\end{array}$ & $\begin{array}{c}\text { Interétnico } \\
n=132\end{array}$ & $\begin{array}{l}\text { Valor } \\
\text { de } p\end{array}$ & $\begin{array}{c}\text { Intraétnico } \\
n=408\end{array}$ & $\begin{array}{c}\text { Interétnico } \\
n=46\end{array}$ & $\begin{array}{l}\text { Valor } \\
\text { de } p\end{array}$ \\
\hline $\mathrm{VCT}^{*}(\mathrm{kcal})$ & $1.990(553)$ & $2.183(612)$ & 0,000 & $2.127(556)$ & $2.259(587)$ & 0,024 & $1.866(520)$ & $1.967^{\star}(636)$ & 0,328 \\
\hline \multicolumn{10}{|l|}{ Carboidrato } \\
\hline$g^{*}$ & $268,3(80,4)$ & $278,1(88,4)$ & 0,000 & $285,9(80,0)$ & $287,8(85,9)$ & 0,000 & $252,3(77,4)$ & $250,2(90,5)$ & 0,002 \\
\hline$\% \mathrm{VCT}$ & $54,1(7,4)$ & $50,8(6,8)$ & 0,000 & $54,1(7,7)$ & $50,9(7,1)$ & 0,000 & $54,1(7)$ & $50,6(6,1)$ & 0,002 \\
\hline \multicolumn{10}{|l|}{ Proteína } \\
\hline $\mathrm{g}^{*}$ & $68,9(22,8)$ & $71,2(23,5)$ & 0,000 & $72,8(23,2)$ & $73,5(22,1)$ & 0,021 & $65,4(21,8)$ & $64,8(26,1)$ & 0,012 \\
\hline$\% \mathrm{VCT}$ & $13,9(2,5)$ & $13,1(2,4)$ & 0,000 & $13,7(2,5)$ & $13,1(2,4)$ & 0,022 & $14,0(2,4)$ & $13,1(2,6)$ & 0,020 \\
\hline \multicolumn{10}{|l|}{ Gordura } \\
\hline$g^{*}$ & $70,5(23,9)$ & $85,7(26,8)$ & 0,000 & $73,1(24,8)$ & $87,6(26,9)$ & 0,000 & $68,3(22,8)$ & $80,1^{\star \star}(25,9)$ & 0,000 \\
\hline \%VCT & $31,9(6,2)$ & $35,4(5,3)$ & 0,000 & $30,8(6,1)$ & $34,8(5,1)$ & 0,000 & $32,9(6,1)$ & $37,1^{\star \star}(5,6)$ & 0,000 \\
\hline Colesterol $(\mathrm{mg})^{\sharp}$ & $189,5(99,3)$ & $224,4(125,8)$ & 0,041 & $207,5(112,1)$ & $233,8(130,4)$ & 0,186 & $173,1(82,8)$ & $197,4(108,6)$ & 0,134 \\
\hline Gordura saturada $(\mathrm{g})^{*}$ & $16,9(6,8)$ & $20,5(7,9)$ & 0,000 & $17,5(6,8)$ & $21,0(7,9)$ & 0,000 & $16,4(6,7)$ & $19,2(7,7)$ & 0,008 \\
\hline Ácido graxo oleico $(\mathrm{g})^{\#}$ & $26,6(9,4)$ & $32,0(10,4)$ & 0,000 & $27,4(9,9)$ & $32,7(10,6)$ & 0,000 & $25,9(8,9)$ & $30,1^{\star \star}(9,6)$ & 0,001 \\
\hline Ácido graxo linoleico $(\mathrm{g})^{*}$ & $11,4(4,2)$ & $12,8(4,4)$ & 0,049 & $11,6(4,4)$ & $13,0(4,5)$ & 0,014 & $11,1(4)$ & $12,3^{\star \star}(4)$ & 0,073 \\
\hline Fibra dietética $(\mathrm{g})^{*}$ & $18,2(7,6)$ & $16,8(7,1)$ & 0,000 & $19,2(8,0)$ & $17,4(7,0)$ & 0,000 & $17,3(7,1)$ & $15,3(7)$ & 0,000 \\
\hline \multicolumn{10}{|l|}{ Micronutrientes } \\
\hline Sódio (mg) & $2.737(1.011)$ & $2.187(896)$ & 0,000 & $2.925(1.071)$ & $2.299(920)$ & 0,000 & $2.566(923)$ & $1.863(740)$ & 0,000 \\
\hline Potássio* (mg) & $2.792(1.054)$ & 2.541 (952) & 0,000 & $2.876(1.071)$ & 2.601 (934) & 0,000 & $2.716(1.035)$ & $2.371(995)$ & 0,000 \\
\hline Cálcio (mg) & $682,1(261,3)$ & $602,2(238,6)$ & 0,000 & $682,8(270,7)$ & $606,2(230,1)$ & 0,000 & $681,4(252,8)$ & $590,4(263,9)$ & 0,000 \\
\hline Vitamina $C^{\sharp}(\mathrm{mg})$ & $230,4(146,2)$ & $191,8(120,5)$ & 0,000 & $233,3(148,1)$ & $192,5(120,4)$ & 0,000 & $227,8(144,6)$ & $189,9(121,9)$ & 0,005 \\
\hline Vitamina $E^{*}(\mathrm{mg})$ & $9,4(3,0)$ & $10,0(3,0)$ & 0,416 & $9,6(3,1)$ & $10,1(2,9)$ & 0,898 & $9,2(2,8)$ & $9,7^{\star \star}(3,1)$ & 0,803 \\
\hline Vitamina B9* (mcg) & $228,7(94,3)$ & $221,1(96,4)$ & 0,000 & $242,3(98,7)$ & $227,6(93,8)$ & 0,000 & $216,3(88,4)$ & $202,7(102,3)$ & 0,004 \\
\hline \multicolumn{10}{|l|}{ Grupo de alimentos (g) } \\
\hline Álcool & $0(0 ; 21,8)$ & $9,9(0 ; 131,6)$ & 0,000 & $11,7(0 ; 152,0)$ & $32,4(0 ; 257,1)$ & 0,067 & $0(0 ; 0)$ & $0^{\star}(0 ; 13,7)$ & 0,002 \\
\hline Doces & $\begin{array}{c}88,5 \\
(41,0 ; 177,0)\end{array}$ & $\begin{array}{c}137,5 \\
(64,0 ; 271,4)\end{array}$ & 0,000 & $\begin{array}{c}101,2 \\
(44,9 ; 213,8)\end{array}$ & $\begin{array}{c}164,0 \\
(65,9 ; 299,4)\end{array}$ & 0,001 & $\begin{array}{c}79,3 \\
(37,8 ; 156,1)\end{array}$ & $\begin{array}{c}118,4 \\
(55,8 ; 200,0)\end{array}$ & 0,092 \\
\hline Hortaliças & $\begin{array}{c}188,9 \\
(138,0 ; 243,2)\end{array}$ & $\begin{array}{c}174,2 \\
(119,6 ; 230,3)\end{array}$ & 0,014 & $\begin{array}{c}189,3 \\
(138,2 ; 248,4)\end{array}$ & $\begin{array}{c}174,6 \\
(131,2 ; 230,2)\end{array}$ & 0,052 & $\begin{array}{c}188,2 \\
(137,4,242,4)\end{array}$ & $\begin{array}{c}174,2 \\
(110,0 ; 232,8)\end{array}$ & 0,087 \\
\hline Frutas e sucos de frutas & $\begin{array}{c}350,7 \\
(202,6 ; 520,7)\end{array}$ & $\begin{array}{c}289,4 \\
(131,6 ; 460,6)\end{array}$ & 0,006 & $\begin{array}{c}361,3 \\
(205,1 ; 537,3)\end{array}$ & $\begin{array}{c}288,7 \\
(123,4 ; 496,0)\end{array}$ & 0,013 & $\begin{array}{c}336,8 \\
(198,2 ; 506,2)\end{array}$ & $\begin{array}{c}295,2 \\
(136,8 ; 444,0)\end{array}$ & 0,140 \\
\hline $\begin{array}{l}\text { Cereais, pães, arroz } \\
\text { e macarrão }\end{array}$ & $\begin{array}{c}481,5 \\
(317,1 ; 556,9)\end{array}$ & $\begin{array}{c}414,5 \\
(298,7 ; 533,1)\end{array}$ & 0,031 & $\begin{array}{c}497,4 \\
(402,3 ; 605,7)\end{array}$ & $\begin{array}{c}469,9 \\
(330,5 ; 545,5)\end{array}$ & 0,006 & $\begin{array}{c}459,6 \\
(271,2 ; 525,8)\end{array}$ & $\begin{array}{c}305,5^{\star} \\
(237,4 ; 464,4)\end{array}$ & 0,009 \\
\hline Leites e derivados & $\begin{array}{c}169,5 \\
(81,0 ; 233,7)\end{array}$ & $\begin{array}{c}166,2 \\
(56,9 ; 236,6)\end{array}$ & 0,449 & $\begin{array}{c}165,4 \\
(60,3 ; 216,3)\end{array}$ & $\begin{array}{c}165,0 \\
(54,3 ; 235,7)\end{array}$ & 0,804 & $\begin{array}{c}173,7 \\
(111,4 ; 244,6)\end{array}$ & $\begin{array}{c}168,8 \\
(72,2 ; 248)\end{array}$ & 0,437 \\
\hline $\begin{array}{l}\text { Carnes, aves, peixes, } \\
\text { ovos e leguminosas }\end{array}$ & $\begin{array}{c}254,5 \\
(167,3 ; 376,7)\end{array}$ & $\begin{array}{c}280,7 \\
(187,5 ; 366,7)\end{array}$ & 0,368 & $\begin{array}{c}278,7 \\
(187,1 ; 409,8)\end{array}$ & $\begin{array}{c}297,7 \\
(198,2 ; 380,0)\end{array}$ & 0,836 & $\begin{array}{c}235,6 \\
(156,2 ; 340,0)\end{array}$ & $\begin{array}{c}222,5^{\star \star} \\
(150,5 ; 337,2)\end{array}$ & 0,518 \\
\hline Óleo, gordura e snacks & $\begin{array}{c}116,1 \\
(63,0 ; 198,5)\end{array}$ & $\begin{array}{c}169,5 \\
(90,5 ; 294,4)\end{array}$ & 0,000 & $\begin{array}{c}124,7 \\
(67,5 ; 237,9)\end{array}$ & $\begin{array}{c}195,8 \\
(94,3 ; 326,2)\end{array}$ & 0,000 & $\begin{array}{c}106,6 \\
(58,2 ; 182,0)\end{array}$ & $\begin{array}{c}156,7 \\
(81,2 ; 67,9)\end{array}$ & 0,026 \\
\hline Missoshiru & $20,0(6,7 ; 57,1)$ & $1,1(0 ; 13,3)$ & 0,000 & $20,0(6,7 ; 57,1)$ & $1,4(0 ; 13,3)$ & 0,000 & $6,7(20,0 ; 57,1)$ & $0(1,1 ; 13,3)$ & 0,000 \\
\hline
\end{tabular}

"Transformação logarítmica para análise estatística; ${ }^{*} p<0,01 \mathrm{e}^{\star \star} p<0,05$ mulheres com casamento interétnico versus homens com casamento interétnico. Análise realizada com valores ajustados. VCT: valor calórico total

A análise das correlações entre as variáveis alimentares e clínico-laboratoriais mostrou coeficientes invariavelmente baixos. O consumo de álcool correlacionou-se aos níveis de HDL-c $(\mathrm{r}=0,105 ; \mathrm{p}<0,01)$, triglicérides $(\mathrm{r}=0,206 ; \mathrm{p}<0,01)$ e à circunferência abdominal $(\mathrm{r}=0,130 ; \mathrm{p}<0,01) \mathrm{e}$, inversamente, à porcentagem de massa gorda $(r=-0,106)$. O consumo de gordura saturada correlacionou-se à circunferência abdominal $(\mathrm{r}=0,108 ; \mathrm{p}<0,01)$, enquanto o de fibras, inversamente, à porcentagem de massa gorda $(r=-0,156$; 
$\mathrm{p}<0,001)$. O consumo do grupo de frutas e sucos correlacionou-se à circunferência abdominal $(\mathrm{r}=0,133$; $\mathrm{p}<0,001)$ e à glicemia de jejum $(\mathrm{r}=0,177 ; \mathrm{p}<0,001)$.

\section{Carboidrato}

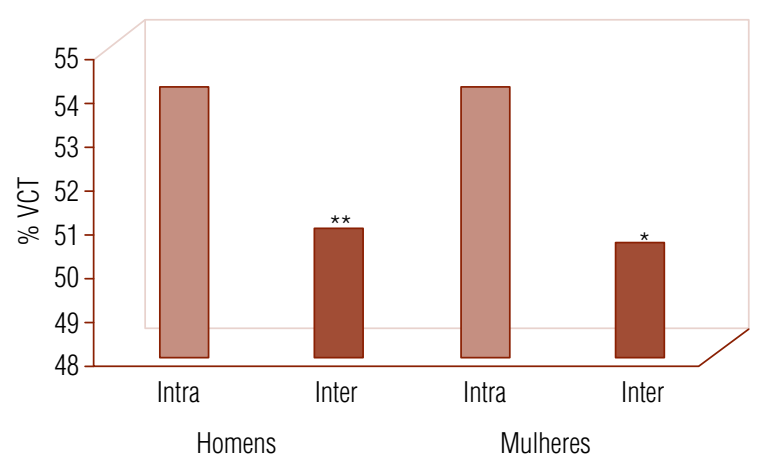

Gordura total

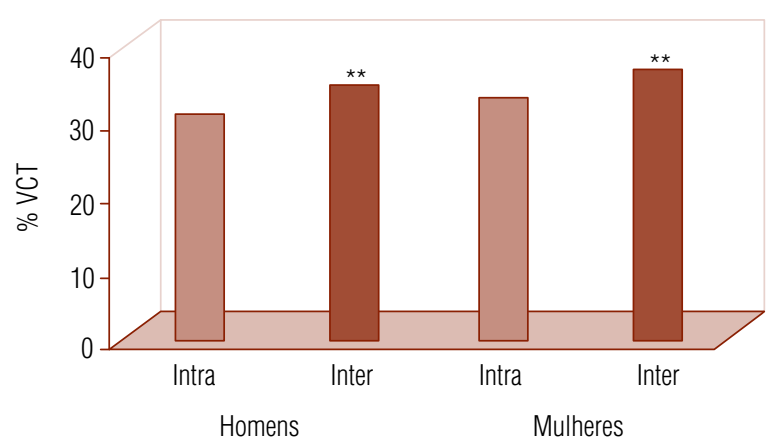

Sódio

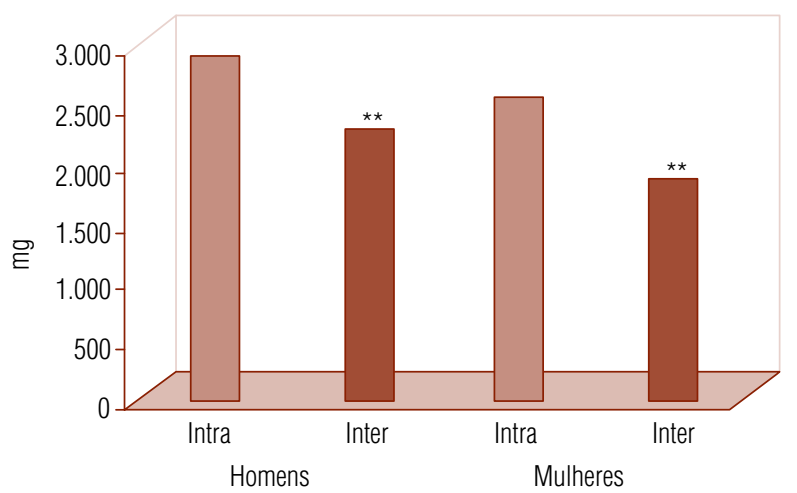

${ }^{*} p<0,01$ versus intra; ${ }^{* \star} p<0,001$ versus intra; $\# p<0,05$ versus homens.

VCT: valor calórico total
Detectaram-se, ainda, correlações significantes $(\mathrm{p}<$ $0,01)$ entre presença de SM com os grupos de frutas e $\operatorname{sucos}(r=0,105)$ e o de leites e derivados $(r=-0,104)$.
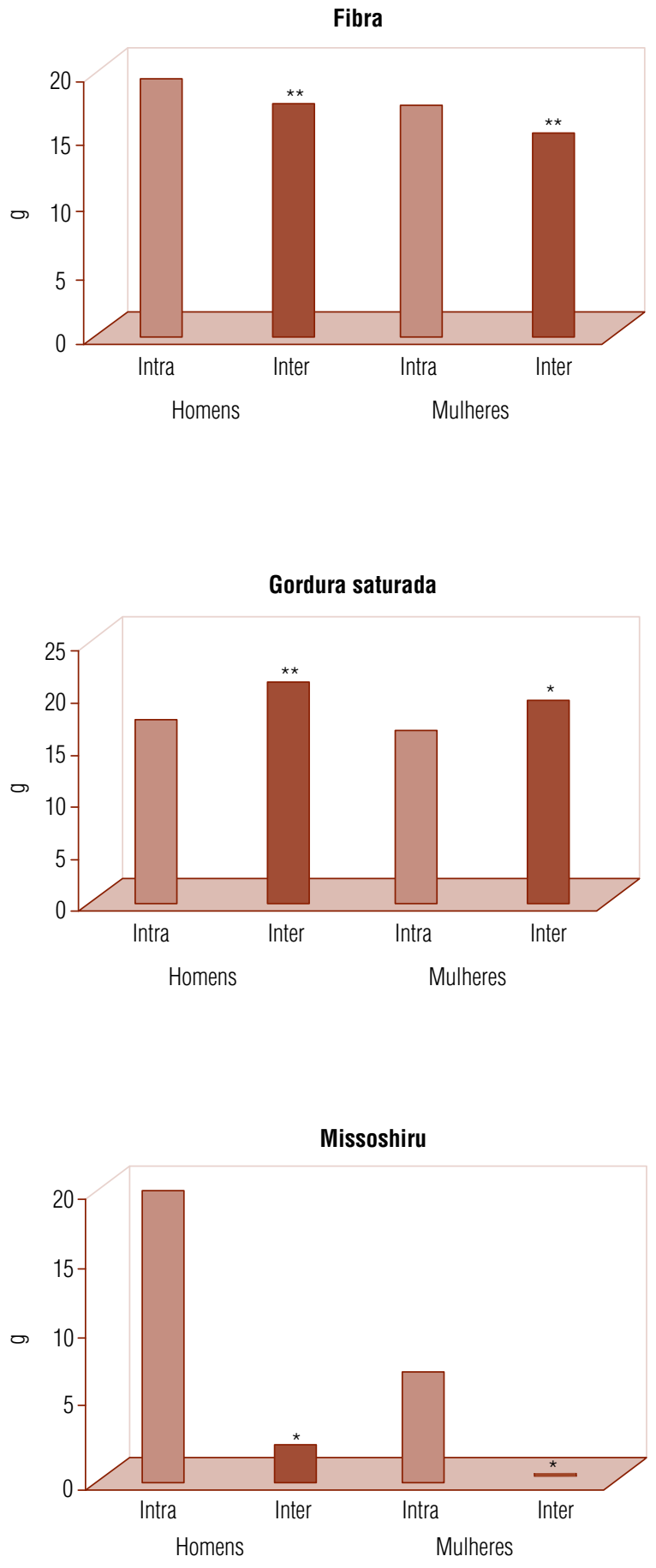

Figura 1. Consumo alimentar de nipo-brasileiros casados, segundo sexo e tipo de casamento. 


\section{DISCUSSÃO}

Este estudo de base populacional fornece subsídios favoráveis à hipótese de que o casamento interétnico pode contribuir para maior ocidentalização dos costumes dos imigrantes japoneses no Brasil, particularmente no que diz respeito aos hábitos alimentares. Apesar da transversalidade do estudo, os achados são condizentes com a ideia de que o consumo de certos nutrientes poderia estar associado à deposição de gordura corporal nos nipo-brasileiros e aos fatores de risco cardiometabólico, que são muito frequentes nessa população $(6,8,11)$. O pressuposto de que o homem nikkei casado com brasileira não nikkei teria dieta mais tipicamente ocidental (rica em gordura) do que quando a esposa é nikkei no casamento interétnico foi confirmado.

Os achados deste estudo sobre as maiores frequências de obesidade central e de SM em nipo-brasileiros que tiveram casamento interétnico, quando comparados àqueles com intraétnico, sugerem um papel deletério do primeiro tipo de união, embora não se possa afirmar a existência de uma relação tipo causa-efeito. É possível que o acúmulo de gordura visceral, gerando resistência à insulina, tenha contribuído para maior ocorrência da SM nos nipo-brasileiros. Yoneda e cols. (32) compararam a prevalência de SM segundo os critérios da International Diabetes Federation (IDF) entre japoneses nativos de Hiroshima e nipo-americanos de Los Angeles, Estados Unidos, com idades entre 30 e 89 anos. Observaram que $38,7 \%$ dos nipo-americanos do sexo masculino apresentaram síndrome, prevalência significantemente maior quando comparada aos japoneses do Japão $(20,1 \%)$ e semelhante à observada nos nipobrasileiros com casamento intraétnico. No presente estudo, as frequências de SM no grupo com casamentos interétnicos foram bem maiores, atingindo diferença significante entre os homens $(53,4 \%$ naqueles com casamento interétnico versus $39,8 \%$ com intraétnico).

Apesar da diferença na frequência de SM no sexo feminino não ter atingido significância estatística segundo o tipo de casamento, este foi o caso em se tratando do diabetes. Estudo de base populacional nesta mesma população já havia relatado altas prevalências de ambas as condições $(7,11)$. Especulou-se que certos hábitos alimentares da mulher com casamento interétnico, como maior consumo de gordura - sobretudo satura$\mathrm{da}$ - e menor ingestão de fibras dietéticas, associados à baixa atividade física, poderiam contribuir, pelo menos em parte, para tais resultados, como indicam alguns estudos (33-35).
Considerando os casamentos interétnicos, evidenciou-se diferença significante nas frequências de hipertrigliceridemia e HDL-c baixo. A maior frequência de hipertrigliceridemia em homens pode estar relacionada ao maior consumo de bebidas alcoólicas; a detecção de correlação significante entre essas variáveis reforça essa hipótese. Limitações do desenho transversal deste estudo não permitem assegurar relação causal, mas é possível que a menor atividade física das mulheres explique parcialmente a maior frequência de HDL-c baixo comparada aos homens. $\mathrm{O}$ fato da diferença encontrada no consumo relativo de gordura (\%VCT) ter sido maior no sexo feminino sugere o impacto que os homens não nikkeis devem exercer em suas esposas nipo-brasileiras no que diz respeito à ocidentalização dos hábitos alimentares.

A análise mais aprofundada da dieta poderia auxiliar no entendimento da forma como o casamento interétnico associou-se ao quadro de morbidade dos nipobrasileiros. Por fatores diversos, principalmente relativos aos instrumentos disponíveis para mensurar dieta - que não são acurados para estimativas absolutas da ingestão de nutrientes $(36,37)$, o estabelecimento de relações causais entre padrões alimentares e doenças é bastante dificultado, o que seria útil para ações preventivas. Visando à prevenção de doenças crônicas, a Organização Mundial da Saúde (OMS) tem recomendado consumo de gordura entre $15 \%$ e $30 \%$ do VCT, na dependência de características individuais. Grupos populacionais altamente ativos e com dieta rica em hortaliças, frutas e cereais integrais podem consumir percentuais maiores de gordura sem comprometer significativamente sua saúde (38). Este parece não ser o caso dos nipo-brasileiros. Especula-se que um consumo aparentemente elevado de gorduras, associado a baixo nível de atividade física, possa contribuir para o perfil desfavorável de morbidade encontrado neste e em outros estudos $(6,7,11,25)$. A ingestão de gordura saturada não deveria ultrapassar 10\% do VCT; a de colesterol dietético, $300 \mathrm{mg} /$ dia; enquanto a ingestão de ácidos graxos poli-insaturados deveria estar entre $6 \%$ a $10 \%$ do VCT (38). Limitações inerentes do questionário de frequência alimentar $(36,37)$ não permitem comparar os resultados do presente estudo a tais recomendações. Um alto consumo de gorduras em migrantes japoneses nas Américas já fora previamente relatado (14,39-41).

Considerando-se a totalidade dos casados com não nikkeis, nota-se que esses indivíduos apresentaram maior consumo energético, de gorduras totais, satura- 
das e colesterol - padrão indesejável do ponto de vista do risco cardiovascular. Porém, encontrou-se também maior ingestão dos ácidos graxos oleico e linoleico. Essas ingestões de gorduras insaturadas não são típicas da dieta japonesa e este achado aponta um ponto favorável da dieta ocidental consumida pelos nipo-brasileiros casados com brasileiros não nikkeis. Por outro lado, alimentos com alta densidade energética (grupos de álcool, óleos e doces), típicos da dieta brasileira, podem ter contribuído para deteriorar o perfil lipídico, fato sugerido pela maior frequência de hipertrigliceridemia no estrato de casamento interétnico. Essas considerações são válidas quando se compara o tipo de casamento no sexo masculino, embora não tenham sido observadas diferenças significantes na mediana de consumo de álcool. Nas mulheres, esse consumo foi baixo e, comparadas pelo tipo de casamento, é possível que aquelas casadas com não nikkeis tenham um consumo maior, podendo ser esse hábito influenciado pelo ambiente ocidental.

Recomenda-se que o consumo de proteína deva ser em torno de $10 \%$ a $15 \%$ do VCT (38). Independente da adequação ou não desse percentual na população nipobrasileira, estudo de coorte dessa população mostrou que o consumo de carnes vermelhas foi preditivo de SM no sexo masculino (16).

O consumo relativo de carboidrato no presente estudo variou entre $50 \%$ e $55 \%$ nos diferentes estratos, enquanto o de fibras, independente do tipo de casamento e sexo, foi menor do que $20 \mathrm{mg} / \mathrm{dia}$. Sabe-se que uma das consequências da ocidentalização da dieta é a diminuição do consumo de fibras. Entretanto, no casamento intraétnico, observou-se que o consumo médio de fibras, vitaminas e minerais foi significantemente maior, o que seria esperado caso esses preservassem mais o padrão de dieta tipicamente japonês. Também compatível com esse comportamento mais tradicional daqueles com casamentos intraétnicos foi a observação de maior consumo do grupo de missoshiru, alimento típico da culinária japonesa, nesse estrato.

Apesar de não empregar método padrão para quantificar a ingestão de sódio, o presente estudo sugere que o consumo médio de sódio foi mais elevado nos estratos de casamento intraétnico. O questionário de frequência alimentar empregado neste estudo era inadequado para avaliar precisamente o consumo desse nutriente, de modo que o objetivo foi somente a comparação entre grupos. Especulou-se que o uso frequente de alimentos preparados com shoyo possa ter contribuído para esses teores na dieta dos casados intraetnicamente. Um ex- cessivo consumo de sódio sugere que medidas educativas devem ser instituídas nesta população, considerando sua sujeição à hipertensão arterial, além da preocupação com câncer gástrico relatado em outras populações japonesas $(42,43)$.

Achado de interesse refere-se ao maior consumo de cálcio naqueles com casamento intraétnico. Leite e derivados, principais fontes de cálcio, não são típicos da dieta japonesa, e este grupo não foi mais consumido pelos casados intraetnicamente. Porém, outras boas fontes de cálcio são os vegetais e os grãos. Enquanto um copo grande de leite tem $300 \mathrm{mg}$ de cálcio e uma fatia média de queijo, $303 \mathrm{mg}$, meia xícara de feijão cozido, de tofu e de brócolis tem, respectivamente, cerca de 41, 258 e $35 \mathrm{mg}$ de cálcio (44). Especula-se que a diferença do consumo de cálcio nos casamentos intraétnicos possa ter ocorrido por conta do consumo de vegetais, especialmente o tofu. Este alimento derivado da soja, de tradição japonesa, estava presente na lista de alimentos discriminados no questionário de frequência alimentar. Vale ressaltar que a soja e seus derivados têm sido apontados como alimentos de proteção cardiovascular, em razão de seus elevados teores de gordura insaturada, fibras, vitaminas, minerais e isoflavona $(45,46)$. Em estudo de coorte, realizado com 40.462 habitantes do Japão que tiveram alta ingestão de soja, observou-se menor risco de doença cerebrovascular e coronariana no sexo feminino, achado atribuído à presença da isoflavona (45). Outros estudos têm sugerido papel protetor de produtos lácteos sobre o metabolismo da glicose $(47,48)$. Caso tais evidências sejam comprovadas e considerando que os nipo-brasileiros são de alto risco para essas doenças (49), esses alimentos estariam bem indicados para essa população.

Apesar de coeficientes baixos, existem evidências na literatura que concordam com os achados desse estudo sobre a correlação entre consumo de álcool e concentrações de HDL-c $(50,51)$, entre circunferência abdominal e aumento de triglicérides (52). A correlação inversa da trigliceridemia com a massa gorda foi, até certo ponto, inesperada; porém, é possível que esse achado expresse mais a gordura subcutânea que conferiria proteção contra distúrbios metabólicos (53). A correlação entre consumo de gordura, sobretudo a saturada, e a circunferência abdominal apresenta um elo em comum: a resistência à insulina. Os benefícios do consumo de fibras alimentares sobre o perfil cardiometabólico têm sido atribuídos principalmente aos seus efeitos no metabolismo glicolipídico $(35,54)$. A indução de sacieda- 
de também é aventada (55), o que estaria concordante com o achado do presente trabalho sobre a correlação inversa entre consumo de fibras com massa gorda. Porém, seu papel no controle da adiposidade corporal em longo prazo não está comprovado. Consumo de frutas e sucos correlacionou-se diretamente à circunferência abdominal e DM; estudos na mesma população já haviam mostrado associação da ingestão desses alimentos com intolerância à glicose (17). A frutose já foi implicada na deterioração da homeostase glicêmica, glicosilação de proteínas e hipertrigliceridemia (56).

Em conclusão, observou-se que indivíduos com casamento interétnico apresentaram pior perfil de risco cardiometabólico e hábitos alimentares menos saudáveis quando comparados aos que se casaram intraetnicamente. É possível que o impacto do casamento com mulher não nikkei contribua de forma mais acentuada para maior ocidentalização da dieta do marido nikkei. O universo amostral deste estudo incluiu apenas indivíduos de primeira e segunda gerações; não se sabe se, para gerações subsequentes, seriam obtidos resultados semelhantes. Entretanto, como a miscigenação tem se tornado cada vez mais frequente, programas educativos sobre hábitos alimentares saudáveis tornam-se fundamentais para promoção da saúde nestes indivíduos de alto risco cardiometabólico.

* Apêndice: Estes autores estão entre os que compõem o Japanese-Brazilian Diabetes Study (JBDS). Em sua integralidade, o grupo é formado por Amelia T. Hirai, Antonio Roberto Doro, Helena Harima, Katsumi Osiro, Mario Kikuchi, Renata Damião e Suely G. A. Gimeno, do Departamento de Medicina Preventiva da Universidade Federal de São Paulo (Unifesp); Laercio J. Franco e Daniela S Sartorelli, do Departamento de Medicina Social da Faculdade de Medicina de Ribeirão Preto da Universidade de São Paulo (USP); Luiza K. Matsumura e Regina C. S. Moisés, da Disciplina de Endocrinologia do Departamento de Medicina da Unifesp; Marly A. Cardoso e Sandra Roberta G. Ferreira, do Departamento de Nutrição da Faculdade de Saúde Pública da USP; Katsunori Wakisaka, do Centro de Estudos Nipo-Brasileiros de São Paulo; Rita Chaim, da Faculdade de Nutrição da Universidade do Sagrado Coração (USC).

Este trabalho contou com apoio financeiro da Fundação de Amparo à Pesquisa do Estado de São Paulo (Fapesp).

Declaração: os autores declaram não haver conflitos de interesse científico neste estudo.

\section{REFERÊNCIAS}

1. Gotlieb SLD, Laurenti R, Souza JMP. Mortality among Japanese migrants living in São Paulo city. J Public Health. 1990;24(6):453-67.
2. Souza RKT, Gotlieb SLD. Mortalidade em migrantes japoneses residentes no Paraná, Brasil. Rev Saúde Pública. 1999;33(3):262-72.

3. Fujimoto WY, Leonetti DL, Kinyon JL, Newell-Morris L, Shuman WP, et al. Prevalence of diabetes mellitus and impaired glucose tolerance among second generation Japanese-American men. Diabetes. 1987;36(6):730-8.

4. Fujimoto WY, Bergstrom RW, Boyko EJ, Kinyoun JL, Leonetti DL, Newell-Morris LL, et al. Diabetes and diabetes risk factors in second- and third-generation Japanese-Americans in Seattle, Washington. Diab Res Clin Pract. 1994;24 Suppl:S24-52.

5. Hara H, Egusa G, Yamakido M, Kawate R. The high prevalence of diabetes mellitus and hyperinsulinemia among the Japanese American living in Hawaii and Los Angeles. Diabetes Res Clin Pract. 1994;24 Suppl:S37-42.

6. Ferreira SRG, lunes M, Franco LJ, lochida LC, Hirai A, Vivolo MA. Disturbances of glucose and lipid metabolism in first and second generation Japanese-Brazilians. Diabetes Res Clin Pract. 1996; 34 Suppl:S59-63.

7. Gimeno SGA, Ferreira SRG, Franco LJ, Hirai AT, Matsumura L, Moisés RS. Prevalence and 7-year incidence of Type II diabetes mellitus in a Japanese-Brazilian population: an alarming public health problem. Diabetologia. 2002;45(12):1635-8.

8. Lerario DDG, Gimeno SGA, Franco LJ, Ferreira SRG. Excesso de peso e implicações da gordura abdominal para a síndrome metabólica em nipo-brasileiros. Rev Saúde Pública. 2002;36(1):4-11.

9. Hirai A, Hirai AT, Brunieri DM, Harima HA, Osiro K, Wakisaka K, et al. Grupo de Estudos do diabetes na comunidade nipo-brasileira (JBDS Group): Diabetes mellitus e doenças associadas em nipobrasileiros. São Paulo: Green Forest do Brasil; 2004.

10. Miyasaka LS, Canasiro S, AbeY, Otsuka K, Tsuji K, Hayashi T, et al. Migration and mental health: Japanese Brazilians in Japan and in Brazil. J Bras Psiquiatr. 2007;56(1):48-52.

11. Rosenbaum P, Gimeno SG, Sanudo A, Franco LJ, Ferreira SR; Japanese-Brazilian Diabetes Study Group. Analysis of criteria for metabolic syndrome in a population-based study of JapaneseBrazilians. Diabetes Obes Metab. 2005;7(4):352-9.

12. Cardoso MA, Hamada GS, Souza JMP, Tsugane S, Tokudome S. Dietary patterns in Japanese migrants to southeastern Brazil and their descendants. J Epidemiol. 1997;7(4):198-207.

13. Gimeno SGA, Ferreira SRG, Franco LJ, lunes M, Osiro K; Grupo de Estudo de Diabetes em Nipo-Brasileiros. Incremento na mortalidade associada à presença de diabetes mellitus em nipobrasileiros. Rev Saúde Pública. 1998;32(2):118-24.

14. Costa MB, Ferreira SRG, Franco LJ, Gimeno SGA, lunes M. Dietary patterns in a high-risk population for glucose intolerance. Japanese-Brazilian Diabetes Study Group. J Epidemiol. 2000;10(2):111-7.

15. CastroTG, Bertolino CN, Gimeno SGA, Cardoso MA. Mudanças no consumo alimentar de nipo-brasileiros residentes em Bauru, São Paulo, Brasil, 1993-2000. Cad Saúde Pública. 2006;22(11):2433-40.

16. Damião R, Castro TG, Cardoso MA, Gimeno SG, Ferreira SR; Japanese-Brazilian Diabetes Study Group. Dietary intakes associated with metabolic syndrome in a cohort of Japanese ancestry. Br J Nutr. 2006;96(3):532-8.

17. Sartorelli DS, Freire RD, Ferreira SR, Cardoso MA; Japanese-Brazilian Diabetes Study Group. Dietary fiber and glucose tolerance in Japanese-Brazilians. Diabetes Care. 2005;28(9):2240-2.

18. Dean K. Sefl-care components of lifestyle: the importance of gender, attitudes ando social situation. Soc Sci Med. 1989;29(2):137-52.

19. Courtenay WH, McCreary DR, Merighi JR. Gender and ethnic differences in health beliefs and behaviors. $\mathrm{J}$ Health Psychol. 2002;7(3):219-31.

20. Nielsen SJ, Adair L. An alternative to dietary data exclusions. J Am Diet Assoc. 2007;107(5):792-9. 
21. Cardoso MA, Stocco PR. Desenvolvimento de um questionário quantitativo de frequência alimentar em imigrantes japoneses e seus descendentes residentes em São Paulo, Brasil. Cad Saúde Pública. 2000;16(1):107-14.

22. Cardoso MA, Kida AA, Tomita LY, Stocco PR. Reproducibility and validity of a food frequency questionnaire among women of Japanese ancestry living in Brazil. Nutr Rev. 2001;21(5):725-33.

23. Fundação IBGE. Tabela de composição de alimentos. Rio de Janeiro: IBGE; 1996.

24. Resources Council, Science and Technology Agency. Standard tables of food composition in Japan. Tokyo: Women's University of Nutrition Press; 1993.

25. Doro AR, Gimeno SGA, Hirai AT, Matsumura LK, Ferreira SRG; JBDS Group. Análise da associação de atividade física à síndrome metabólica em estudo populacional de nipo-brasileiros. Arq Bras Endocrinol Metab. 2006;50(6):1066-74.

26. World Health Organization, International Association for the Study of Obesity, International Obesity Task Force. The Asia-Pacific Perspective: Redefining obesity and its treatment. Sydney: Health Communications; 2000

27. Vieira MLC, Sproesser AJ. V Diretrizes Brasileiras de Hipertensão Arterial. Arq Bras Cardiol. 2007;89(3):e24-e79.

28. Expert Committee on the Diagnosis and Classification of Diabetes Mellitus. Report of the Expert Committee on the Diagnosis and Classification of Diabetes Mellitus. Diabetes Care. 2003;26(Suppl 1):S5-20.

29. Executive Summary of theThird Report of the National Cholesterol Education Program (NCEP). Expert Panel on detection, evaluation and treatment of high blood cholesterol in adults (Adults Treatment Panel III). JAMA. 2001;285(19):2486-97.

30. International Diabetes Federation [Internet]. The IDF consensus worldwide definition of the metabolic syndrome, 2006. [cited 2009 Jun 19]. Disponível em: http://www.idf.org/webdata/docs/ IDF_Meta_def_final.pdf

31. Willet WC, Stampfer MJ. Implications of total energy intake for epidemiologic analyses. In: Willet WC, editor. Nutritional Epidemiology. New York: Oxford University Press; 1998. p. 272-301.

32. Yoneda M, Yamane K, Jitsuiki K, Nakanishi S, Kamei N, Watanabe $\mathrm{H}$, et al. Prevalence of metabolic syndrome compared between native Japanese and Japanese-Americans. Diabetes Res Clin Pract. 2008;79(3):518-22.

33. van Dam RM, Willett WC, Rimm EB, Stampfer MJ, Hu FB. Dietary fat and meat intake in relation to risk of type 2 diabetes in men. Diabetes Care. 2002; 25(10):417-24.

34. Thanopoulou AC, Karamanos BG, Angelico FV, Assaad-Khalil SH, Barbato AF, Del Ben MP, et al. Dietary fat intake as risk factor for the development of diabetes: multinational, multicenter study of the Mediterranean Group for the Study of Diabetes (MGSD). Diabetes Care. 2003;26(2):302-7.

35. MacKeown NM, Meigs JB, Liu S, Wilson PW, Jacques PF. Wholegrain intake is favorably associated with metabolic risk factors for type 2 diabetes and cardiovascular disease in the Framingham Offpring Study. Am J Clin Nutr. 2002;76(2):390-8.

36. Liu K. Statistical issues related to semiquantitative food-frequency questionnaires. Am J Clin Nutr. 1994;59(1 Suppl):262S-5.

37. Freedman LS, Midthune D, Carroll RJ, Krebs-Smith S, Subar $\mathrm{AF}$, Troiano RP, et al. Adjustments to improve the estimation of usual dietary intake distributions in the population. J Nutr. 2004;134(7):1836-43.

38. World Health Organization (WHO). Diet, nutrition and the prevention of chronic diseases. Geneva; WHO/FAO;2003 (Technical report series 916).

39. Fujimoto WY, Bergstrom RW, Boyko EJ, Chen K, Kahn SE, Leonetti $\mathrm{DL}$, et al. Type 2 diabetes and the metabolic syndrome in Japanese Americans. Diabetes Res Clin Pract. 2000:50 Suppl 2:S73-6.
40. Takata Y, Maskarinec G, Franke A, Nagata C, Shimizu H. A comparison of dietary habits among women in Japan and Hawaii. Public Health Nutr. 2004;7(2):319-26.

41. Freire RD, Cardoso MA, Gimeno SG, Ferreira SR; Japanese-Brazilian Diabetes Study Group. Dietary fat is associated with metabolic syndrome in Japanese-Brazilians. Diabetes Care. 2005;28(7):1779-85.

42. Tsugane S, Tsuda M, Gey F, Watanabe S. Cross-sectional study with multiple measurements of biological markers for assessing stomach cancer risks at the population level. Environ Health Perspect. 1992;98:207-10.

43. KawanoY, Ando $\mathrm{K}$, Matsuura $\mathrm{H}$, TsuchihashiT, Fujita T, Ueshima $\mathrm{H}_{\text {; }}$ Working Group for Dietary Salt Reduction of the Japanese Society of Hypertension. Report of the Working Group for Dietary Salt Reduction of the Japanese Society of Hypertension: (1) Rationale for salt restriction and salt-restriction target level for the management of hypertension. Hypertens Res. 2007;30(10): 879-86.

44. Cardoso MA. Nutrição Humana. Rio de Janeiro: Guanabara Koogan; 2006.

45. Kokubo Y, Iso H, Ishihara J, Okada K, Inoue M, Tsugane S; JPHC Study Group. Association of dietary intake of soy, beans, and isoflavones with risk of cerebral and myocardial infarctions in Japanese populations: the Japan Public Health Center-based (JPHC) study cohort I. Circulation. 2007;116(22):2553-62.

46. Sacks FM, Lichtenstein A, Van Horn L, Harris W, Kris-Etherton P, Winston M; American Heart Association Nutrition Committee. Soy protein, isoflavones, and cardiovascular health: an American Heart Association Science Advisory for professionals from the Nutrition Committee. Circulation. 2006;113(7):1034-44.

47. Pittas AG, Lau J, Hu FB, Dawson-Hughes B. Review: The role of vitamin $\mathrm{D}$ e calcium in type 2 diabetes. A systematic review and meta-analysis. Endocrinol Metab. 2007;92(6):2017-29.

48. Pereira MA, Jacobs DR, Van Horn L, Slattery ML, Kartashov Al, Ludwig DS. Dairy consumption, obesity and the insulin resistance syndrome in young adults: the CARDIA Study. JAMA. 2002;287(16):2081-9.

49. Siqueira AAF, Franco LJ, Gimeno SGA, Matsumura LK, Barros-Junior N, Ferreira SRG for the JBDS Group. Macrovascular disease in a Japanese-Brazilian population of high prevalence of metabolic syndrome: associations with classical and non-classical risk factors. Atherosclerosis. 2007;195(1):160-6.

50. Thornton J, Symes C, Heaton K. Moderate alcohol intake reduces bile cholesterol saturation and raises HDL cholesterol. Lancet. 1983;2(8354):819-22.

51. Sillanaukee $P$, Koivula T, Jokela H, Pitkäjärvi T, Seppä K. Alcohol consumption and its relation to lipid-based cardiovascular risk factors among middle-aged women: the role of $\mathrm{HDL}(3)$ cholesterol. Atherosclerosis. 2000;152(2):503-10.

52. Turcato E, Bosello O, Di Francesco V, Harris TB, Zoico E, Bissoli $L$, et al. Waist circumference and abdominal sagittal diameter as surrogates of body fat distribution in the elderly: their relation with cardiovascular risk factors. Int J Obes Relat Metab Disord. 2000;24(8):1005-10.

53. Tanaka M, Koga R, Tsuda H, Imai K, Abe S, Masuda T, et al. Subcutaneous fat accumulation shows a beneficial correlation with serum cholesterol in postmenopausal Japanese women. Exp Biol Med (Maywood). 2007;232(8):1064-70.

54. Rimm EB, Ascherio A, Giovannucci E, Spielgman D, Stampfer MJ, Willett WC. Vegetables, fruit and cereal fiber intake and risk of coronary heart disease among men. JAMA. 1996;275(6):447-51.

55. Brown L, Rosner B, Willett WW, Sacks FM. Cholesterol-lowering effects of dietary fiber: a meta-analysis. Am J Clin Nutr. 1999;69(1):30-42.

56. Teff KL, Elliott SS, Tschöp M, KiefferTJ, Rader D, Heiman M, et al. Dietary fructose reduces circulating insulin and leptin, attenuates postprandial suppression of ghrelin, and increases triglycerides in women. J Clin Endocrinol Metab. 2004;89(6):2963-72. 